$R M x A C, \mathbf{5 3}, 1-7(2021)$

(C) 2021: Instituto de Astronomía, Universidad Nacional Autónoma de México

https://doi.org/10.22201/ia.14052059p.2021.53.02

\title{
ASTRONOMICAL OBSERVATORIES: CONSOLIDATION OF THE MODERN OBSERVATORY BETWEEN THE XVIIITH AND THE XXTH CENTURIES
}

\author{
Miguel Ángel Castro Tirado ${ }^{1,2}$
}

\begin{abstract}
RESUMEN
En este artículo exponemos desde un punto de vista arquitectónico cómo el Observatorio Moderno se expande desde Europa hasta el resto del mundo, y cómo, a lo largo de este proceso, se desarrollan y consolidan ciertas características que lo hacen cada vez más propicio para el desarrollo de la actividad astronómica.
\end{abstract}

\section{ABSTRACT}

In this work we present from an architectural point of view how the Modern Observatory spreads from Europe to the rest of the World, and how, throughout this process, certain characteristics are developed and consolidated that make it increasingly paving the way for development of astronomical activity.

Key Words: history and philosophy of astronomy — telescopes

\section{INTRODUCTION}

Since the fascination of the human being by the celestial bodies that moved through the sky was awakened in Prehistory, the first structures that can be identified as predecessors of astronomical observatories began to emerge. These elementary constructions gave rise to more and more complex ones in a process that lasted for several thousand years until the first modern observatory appeared in the 16th century: Uraniborg (Castro Tirado 2019a).

The development of the modern observatory will continue for the next two centuries in a trial and error process with ups and downs that will coincide with the appearance of the telescope, which will become a milestone that will change the paradigm of astronomy and, therefore, of the astronomical observatories themselves.

Thus, in the 18th century, the modern observatory consisted of a building conceived for the study of astronomy, conditioned by the instruments and functions required for research as well as by the needs of the users who worked, or even lived inside (Castro Tirado 2019b).

\section{ADAPTATION TO ASTRONOMICAL INSTRUMENTS}

Observatories such as the one in Paris, Greenwich or Cádiz, hosted buildings whose most elementary features were typical of constructions that had nothing to do with astronomy (residences, palaces or

\footnotetext{
${ }^{1}$ Instituto de Astrofísica de Andalucía (IAA-CSIC), Granada, Spain.

${ }^{2}$ Escuela Técnica Superior de Arquitectura, Universidad de Málaga, Málaga, Spain.
}

fortresses) although during their construction they were adapted to accommodate the astronomical function. For this reason, in addition to the spaces for observation itself, they incorporated calculation rooms, archives or instrument warehouses as areas for astronomy. The rest of the construction housed the other characteristic uses of the dwelling of the main observer or his assistants.

The construction of the Radcliffe Observatory began in Oxford in 1772 (see Figure 1). This building presented the caracteristic conditions of an astronomical activity according to the methods and needs of its time. For this reason, given that the observation of the meridian plane required certain conditions, the building had a specific orientation with openings directed for this purpose. Similarly, the use of long refracting telescopes demanded high and spacious rooms with corresponding elongated windows similar to the Octagon Room of its predecessor, the Greenwich Observatory. All this would be finally including in the design of the observatory with rooms adapted for zenith and transit observation on the ground floor, and a space adapted to work with long refractors on the upper floor (see Figure 2). The astronomical adaptation of the building was remarked by making the residence of the director independent of the observatory. This was separated but connected to the main building by a corridor.

The traces of the building were arranged in a canonical way according to the standards of astronomy of its time, that is, with its main side aligned parallel to the east-west axis and the minor side oriented from north to south. 


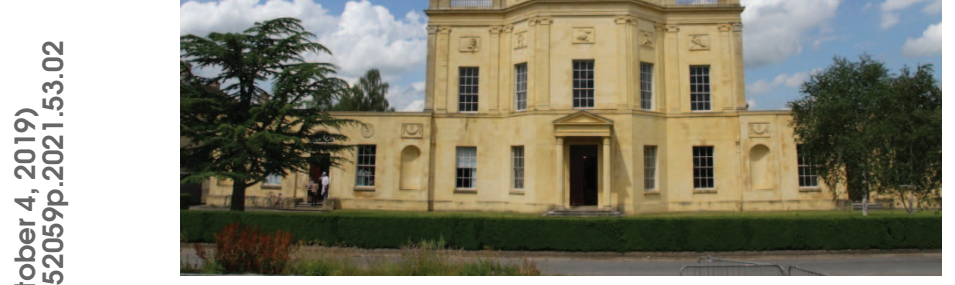

Fig. 1. The Radcliffe Observatory.

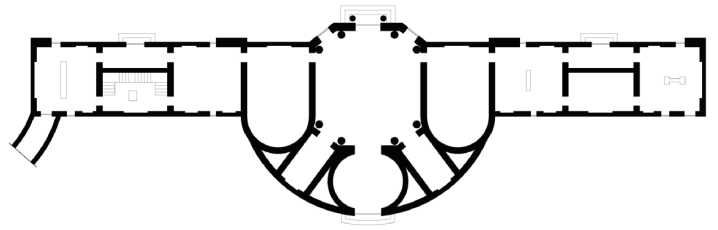

Fig. 2. Plant of the Radcliffe Observatory.

On the other hand, this project also aimed that astronomical observation and the teaching of this science be linked and promoted around these facilities and equipment, which would represent one of the first institutions in the world to combine astronomy teaching and research.

Its location, quite far away from the city center as well as from other university constructions, ensured an isolation that, despite making the access for students more difficult, gave it better conditions for observation, such as a lower pollution and less presence of visuals obstacles in the surroundings.

Following the developments at the Radcliffe Observatory, some years later, in 1783, the development of the Dunsink Observatory started (see Figure 3) (Hutchins 2008). This observatory would start from the selection of the instruments for the institution, in order that the building that was built would adapt to the needs of the scientific equipment, that is, that the function contained (astronomical observation) would condition the design and shape of the container (the building) (Ball 1985).

The project paid great attention to all the details that could affect the quality of the observations, considering its situation and structural stability as the

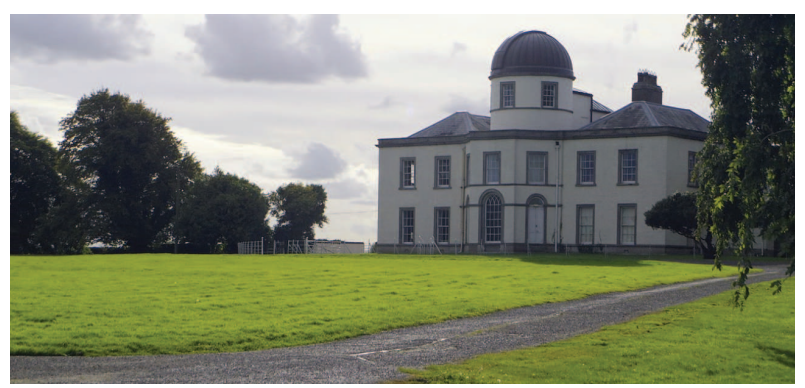

Fig. 3. Dunsink Observatory.

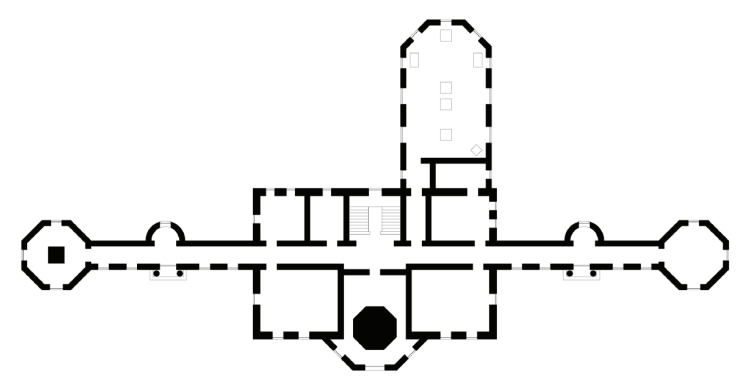

Fig. 4. Plant of Dunsink Observatory.

main ones (Ussher 1787), despite the fact that it also stood out for its climate control and high operability. The location of the building was intended to move away from the increasing pollution of the city while looking for an elevated position that would free it from visual obstacles to avoid the need for an elevated construction that was less stable. And precisely this structural stability would be one of the great advances of this observatory. The construction incorporated foundations and independent supports for the observation instruments, isolating them from the structure of the rest of the building by means of soft and elastic elements.

The climatic attention is perceived in the building's floor itself (see Figure 4), organized considering the prevailing winds in the area. In addition, the observation openings of the meridian room were continuous from north to south and have practicable panels that allow the size of the opening to be adjusted. Furthermore, to avoid thermal differences between the interior and exterior of this room, there were protected ventilation holes to avoid air currents that could produce some vibration.

However, the mobile dome solution that sheltered the main telescope highlighted above all the pointed features before mentioned. This innovation that covered the observation space by means of a hemispher- 
ical structure could rotate, which together with an adjustable opening system allowed visual access to any point in the sky, managed to protect both the instrument itself and the observer from wind or cold.

All this will be possible by considering the telescope as the protagonist of astronomical research, giving it a privileged position and its optimal use being the center of architectural design. In this sense, this project will be a clear example of the importance of the collaboration between the architect (Myers, also known by Moyers) and astronomers (Ussher with the collaboration of Maskelyne) (Dixen 1950; Morton 1988a). Although part of the design was modified during construction to eliminate the north and south wings, the progress of this project defined the essential characteristics that would define the observatories for years to come.

During the 19th century, popular belief still identified an astronomical observatory as a tall tower (Morton 1988b), when more than a hundred years ago that stream had been abandoned. Throughout the last centuries there had been several substantial advances in the design of observatories, all of them occurred to satisfy the needs of astronomical progress. The observatories that were going to appear during the 18th and 19th centuries, and even up to the beginning of the 20th, would be characterized by clear parameters. The building would need a low-height part to place the quadrants and the meridian transit instrument that was characterized by one or more continuous openings (in walls and ceiling) perfectly aligned from north to south, which would mean an elongated volume with its greater side oriented from east to west. On the other hand, the building should have an area for refraction telescopes, either in a polyhedral plan room with high windows or by means of one or more domes (Chapman 2013).

Definitely the observatories showed a series of strategies designed to satisfy the requirements that astronomical research was demanding. As specialized buildings, they were the architectural-constructive result of a specific scientific function. Therefore, the characteristics that defined the modern observatory were derived from the understanding and correct interpretation of the conditions specified by a science in constant development (Londoño 2007a).

The truth is that the observatories of this period were far from resembling the popular image of them. This was so because its evolution was continuous in pursuit of the needs of a constantly changing astronomy to which architecture had to adapt.

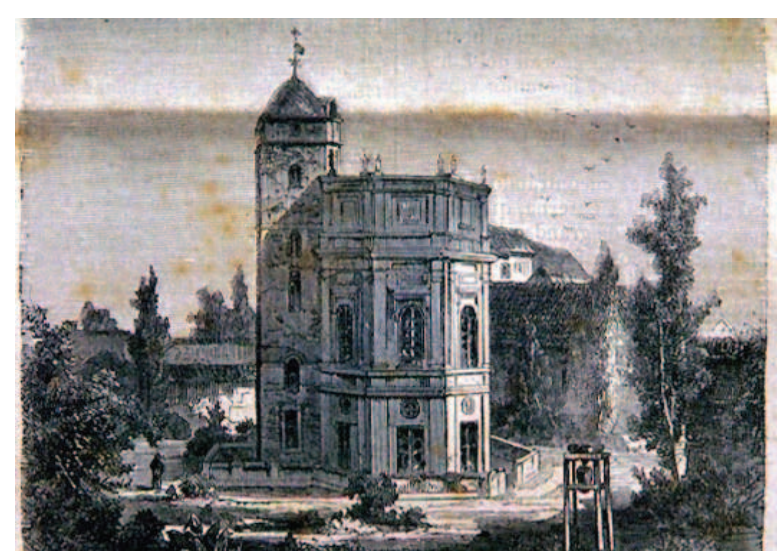

Fig. 5. The Bogotá Observatory.

\section{SPREADING AROUND THE WORLD}

The development experienced from Uraniborg to the culmination of the modern observatory took place, with different ups and downs, on the basis of almost exclusively technical-scientific arguments through important qualitative leaps defined and presented in concrete projects (Paris, Greenwich, Radcliffe, Dunsink...) whose advances would be gradually incorporated into subsequent proposals. In this way, the design of the building responded fundamentally to get the best possible conditions for the development of astronomy.

Having reached standards that covered the basic needs of the scientific function, throughout the 18th century, and especially towards its end, numerous astronomical observatories began to appear throughout Europe spreading later on to the rest of the world, with many astronomical centers emerging around our planet.

At a time when the exploration and colonization trips of the 18th century the growing interest in scientific knowledge in fields such as botany, zoology or astronomy was fostered, also considering that an economic benefit could be derived. The newly opened Bogotá Observatory (Figure 5), became the first observatory in the American continent and the pioneer of the research centers in the Spanish colonies (Londoño 2007b).

In that same colonial context, the British government had commercial and strategic interests to promote the development of Astronomy. In addition, this science had an important impact on navigation and cartography, crucial issues to maintain control of their territories and even expand them. The British East India Company already had an observatory in Madras (Figure 6), established in 1792 from a pri- 


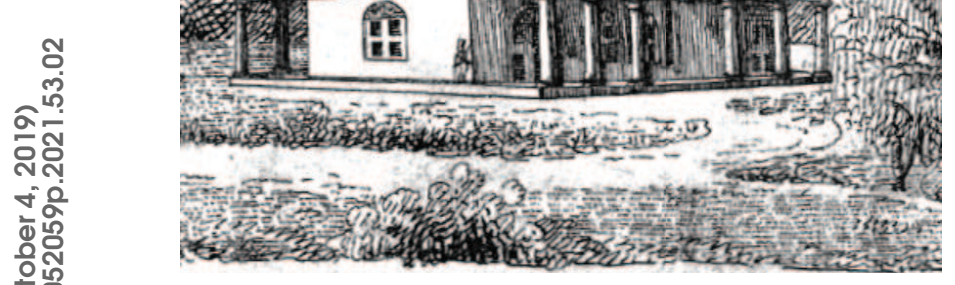

Fig. 6. The Madras Observatory.

vate observatory, and another in Colaba, founded in 1832 , a place that would not reach the middle of the century (Kurian 2008).

Since South Africa was established as a colony from Great Britain at the beginning of the 19th century, the demographic increase of British immigrants led to the development of schools or libraries, as well as a scientific-research interest that together with the influence of the British astronomical community led to establish a permanent observatory there (Chapman 1914). Although this observatory (dubbed The Cape of Good Hope Observatory) was founded as an institution in 1820, becoming the first scientific institution in Africa (Figure 7), its construction would not be completed until 1928 (Glass 2017).

Given that the British effort to found a national observatory was directed at that period towards the Cape of Good Hope Observatory (in South Africa), Thomas Brisbane, an amateur astronomer who acceded to the post of governor of New South Wales (Australia), promoted his private observatory in Parramatta (near Sidney) in 1922 (Bhathal 2011).

Although the evolution of this science remained constant over time with various advances and even with the birth of astrophysics as a branch of astronomy with its own particularities, the changes would not always be reflected in significant variations in the design of the observatory, which continued to maintain a mixed-use programme in which the strictly observation spaces (occupied and characterised by the instruments) coexisted with other spaces where the activities derived from these observations took place (data analysis, discussion of results...), and other accessory spaces, intended for the particular functions of certain observatories (conference rooms, libraries...) and other service functions (bedrooms,

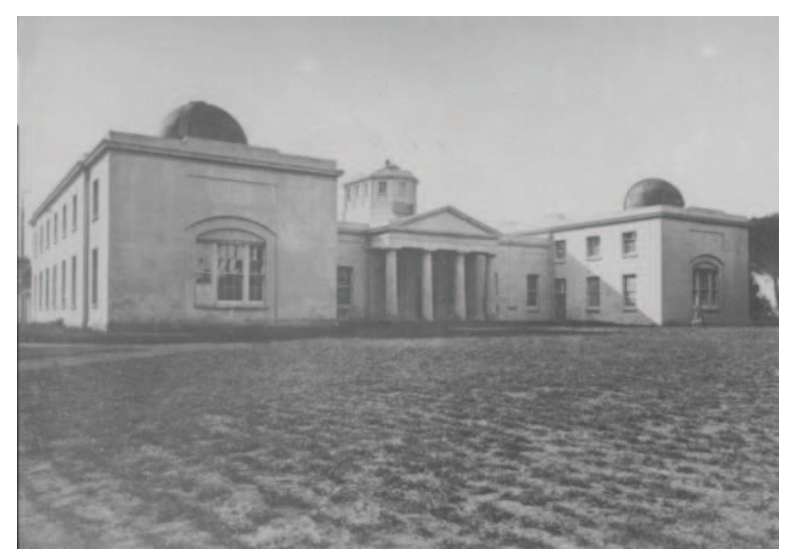

Fig. 7. The Cape of Good Hope Observatory.

storage rooms...) which, on occasion, were moved to one or more independent buildings. However, this cannot be applied to the first observatories that appeared far from Europe, as the limited conditions of the colonies gave rise to elementary and modest constructions that were far from the astronomical centres of the old continent.

\section{A RACE FOR THE LARGEST REFRACTOR}

Although up to this moment it was the meridian quadrant (Lafuente 1988), the instrument that had characterized astronomy prior to this period, and therefore the observatories, the telescope in the 19th century started to acquire an increasingly important role, transcendental for this science, which was necessarily reflected in a significant change in the design of observatories. This aspect would also be accentuated by an insistent aspiration to obtain a better image definition, as it happened two centuries before when Hooke, Huygens or Hevel began to use this instrument for astronomical purposes. This meant an increase in the size of the telescope and, therefore, of all the main or secondary systems on which it depended. In other words, although some moderatesized research centers were still being built, the scale of the main observatories was going to increase exponentially as it happened in the race to get the largest refractor of its time.

In Figure 8 we show a chronological sequence of the project plans of some representative astronomical observatories, in which the dimension and position of their domes are highlighted. All the plans are presented to the same scale, so that the increase in size in the domes and, therefore, of the instruments they contained, can be compared at a glance. 


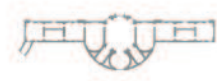

1772 Radcliffe

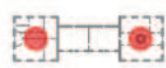

1825 Hamburg

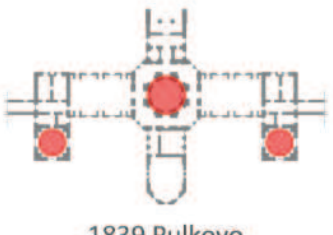

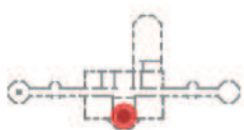

1783 Dunsink

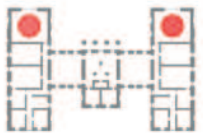

1828 Cape of Good Hope

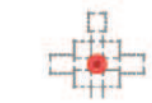

1844 Washington

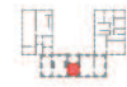

1790 Seeberg

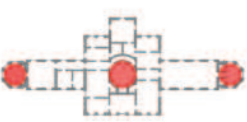

1834 Helsinki

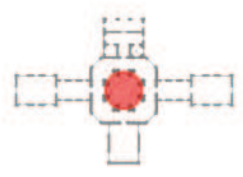

1861 Lisbon

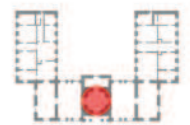

1816 Göttingen

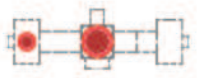

1839 Harvard

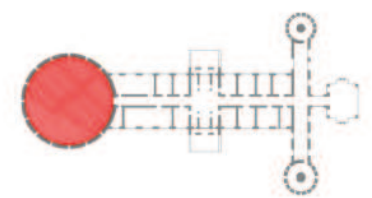

1897 Yerkes

Fig. 8. Plans of some representative astronomical observatories.

This dispute to get the largest telescope in the world, not only represented scientific desire but also meant ambition for fame, prestige and recognition. Thus, this fight began with the great Pulkovo refractor (38 $\mathrm{cm}$ in diameter) of 1839 , surpassed by the Washington $(66 \mathrm{~cm})$ one in 1844 . This competition accelerated towards the end of the century when the new Pulkovo instrument was installed $(76 \mathrm{~cm})$ in 1885 , followed by the Nice one $(77 \mathrm{~cm})$ in 1886 and later when the Lick's main telescope $(91 \mathrm{~cm})$ was installed in 1888. The contest of the great refractors would extend until the deployment of the Yerkes refractor $(102 \mathrm{~cm})$ in 1897 , that at present times continues being the largest refractor telescope in the world.

In addition to the technical difficulties that complicated this redundant growth of instruments, it would be a change in the prevailing model of telescopes that would end up putting an end to this race. Although telescopes based on mirrors had been installed in observatories for decades, their role had always been secondary in relation to the importance of large refractors. However, its importance was going to increase thanks to the technological advances that would make it possible to manufacture the required mirrors in parallel with the development of astrophysics itself.

Regardless of the type of instrument to be considered, the exponential growth achieved during these disputes reached such a degree that the different projects highly influenced the architecture of the buildings that were supposed to host the telescopes. This would imply an increase in the size of the buildings housing the telescopes producing in turn a large amount of surplus space that could be devoted to other uses.

\section{NEW FEATURES}

A common circumstance for the observatories of this period is the constant search for favorable conditions to look at the sky with increasingly precise instruments and, therefore, more susceptible to being negatively affected by movement, climatic changes, humidity or the pollution and lighting coming from urban centers. However, this claim was redundantly contravened by circumstances not originally foreseen, such as the vibrations of nearby trains, the smoke from the factories or the light of the cities that grew invading the limits of some observatories that had to be protected or moved more and more away from all these detrimental aspects.

Other characteristics that evolve during this diffusion period will be the modification and expansion of the program of uses or the incorporation of secondary functions to the observatories.

The most relevant removal that occurred throughout these years was that of the director's residence. 
This house, in which the main observer used to live with his family, and was even accompanied by other rooms for temporary stays and rooms for the service used to have all kinds of comforts and usually remained integrated or attached to the building itself until it began to lose relevance in the project. This caused that residence to end up as an independent construction in the immediate vicinity and, finally, it would end with its disappearance or its absolute segregation.

This loss of the residential area implied a liberation of space that would be occupied by other main functions derived from the basic activity of the observatory such as laboratories, calculation rooms, photographic rooms, etc.; and for other secondary uses that provide the building with service, such as offices, waiting rooms or libraries. However, beyond what has already been stated, the opening of these research centers to students, people interested in the subject and even to the general public would entail the occasional inclusion of other performances such as conference rooms, classrooms, exhibition halls or coffee shops.

Precisely, this link between astronomy and education, which can be traced to Ancient Greece or perhaps beyond, which is maintained during the period of the first Islamic observatories and which would be associated even with naval training, would converge with the university at the early seventeenth century in Leiden and with some cases throughout the following century, until it was finally established during the nineteenth century, when some colleges or university departments founded their own astronomical centers or were associated with an existing one establishing a relationship that would consolidate the model of astronomical observatory destined to the formation or teaching.

Likewise, another of the most representative changes in the substantial evolution of the nineteenthcentury observatory refers to the origin of these institutions, specifically the germ of these scientific centers. If until that moment monarchs or governments financed and supported these projects based on strategic or prestigious motivations, in the 19th century private organizations or promoters would appear building their own observatories both for their private use and for their public transfer or donation to any institution.

While, on the one hand, large national observatories continued to emerge in some of the states that did not yet have one (such as Russia or Portugal), on the other, astronomy would begin to transcend from mere curiosity to a true interest for a part of

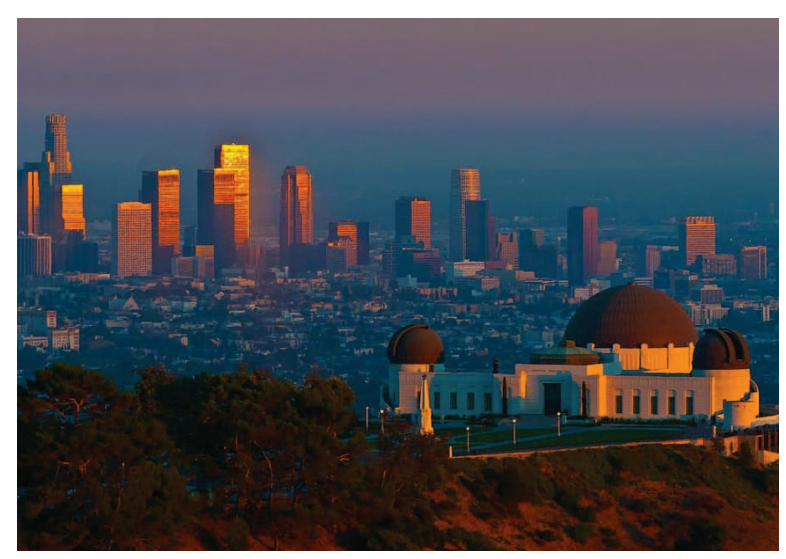

Fig. 9. The Griffith Observatory.

the wealthy population that, in an expansionist and colonization context, would cause the foundation of private or semi-private observatories in new settlements in the most remote locations (such as in India or Australia).

When these research centers, traditionally restricted to a scientific elite, begun to become permeable (at least partially) to a non-specialized public through classes, conferences or seminars and when the media started to show their achievements, an interest in this science began to be awaken. This led to a wide audience knowing about these particular observatories, even promoting them as a tourist attraction. This trend lasted until it reached the significance of an observatory as a recognizable element of a region or population, or even until becoming popular or even a cinematographic icon (Figure 9).

\section{CONCLUSIONS}

However, before reaching the 20th century, the colonial expansion and the popularization of this science had led astronomical observatories to spread throughout the world, reaching the five continents.

During this period, observatories with a great variety of spatial configurations emerged, with different functional concepts and with different degrees of openness, which gave rise to very heterogeneous projects. Even recognizing some deficits and misconceptions typical of inexperience, it is evident that by maintaining fundamental criteria, there were infinite solutions through which architecture can generate the precise conditions for astronomical research and high-quality observations.

These criteria were:

- A favorable location both to overcome obstacles that limit observations and to avoid damaging 
environmental circumstances, such as pollution, vibrations or fog.

- Correct situation for the installation of observation instruments that require a certain orientation.

- Thermal stability to avoid deformations in the lenses or tubes of the telescopes that could distort the observations.

- Structural stability to prevent the transmission of any possible vibration or movement to the observation instruments.

- Attention to users to provide comfortable working or resting conditions that ensure their performance during observations or calculations.

At this point, although the architecture had to adapt to the astronomical requirements demanded and to the conditions of the large telescopes, the project definition of the building went hand in hand with the instruments provided for it, which in many cases were commissioned simultaneously. In this way, the observatory could be designed to support, praise and promote astronomy.

Acknowledgments: I acknowledge fruitful comments from A. J. Castro-Tirado and G. Olmedo. This work has been supported by the Spanish Science Ministry "Centro de Excelencia Severo Ochoa" Program under grant SEV-2017-0709. I am also grateful to Junta de Andalucía grant under project P12-TIC-2839.

\section{REFERENCES}

Ball, R. S. 1985, "Great Astronomers", p. 213

Bhathal, R. 2011, "Some scientific aspects of Parramatta Observatory"r, Journal and Proceedings of The Royal Society of New South Wales,Vol. 145, pp. 111-113

Chapman,S. 1914, Obs, 37, pp. 92-93

Chapman, A. 2013 "Thomas Hornsby and the Radcliffe Observatory", p. 205

Castro Tirado, M. A. 2019a, "The Astronomical Observatory: a dialogue between science and architecture", PhD Thesis, Universidad de Málaga, Spain, pp. 68-69

Castro Tirado, M. A. 2019b, RMxAC, 51, p.1-8

Dixon, F. E. 1950, "Dunsink Observatory and its astronomers", p. 33

Glass, I. 2017 "Royal Observatory, Cape of Good Hope, Republic of South Africa", Heritage Sites of Astronomy and Archaeoastronomy in the context of the UNESCO World Heritage Convention, pp. 117-135

Hutchins, R. 2008, "British University Observatories 1772-1939", p. 25

Kurian, P. 2008, "History of Astronomical Science in Kerala", PhD thesis University of Keralaa, India, pp. 144-146

Lafuente, A., Sellés, M. 1988, "El Observatorio de Cádiz (1753-1831)", p. 170

Londoño, J.; Morales, A. 2007a, "Observatorio Astronómico de Bogotá", pp. 38-39 2007b, pp. 17-22

Morton-Gledhill, R. 1988a, "The architecture of astronomy in the British Isles: a general study", p. 241 . 1988b, p. 235

Reade, V. 1972, "The Radcliffe Observatory, Oxford, 1772-1929", p. 377

Ussher, H. 1787, "Account of the Observatory Belonging to Trinity College, Dublin", p. 8 